\title{
MÉTODOS DE PROPAGAÇÃO DO PORTA-ENXERTO 'OKINAWA' E ESPAÇAMENTOS: EFEITOS NO DIÂMETRO DO TRONCO, FENOLOGIA E PRODUÇÃO DE GEMAS EM PESSEGUEIROS ‘AURORA-1’1
}

\author{
NEWTONALEX MAYER ${ }^{2} \&$ FERNANDO MENDES PEREIRA ${ }^{3}$
}

RESUMO - O presente trabalho teve por objetivo estudar o diâmetro do tronco, a fenologia e a produção de gemas em pessegueiros 'Aurora-1', enxertados no porta-enxerto 'Okinawa' propagado por sementes e por estacas herbáceas, em três espaçamentos $(6 \times 2 \mathrm{~m}$, $6 \times 3 \mathrm{~m} \mathrm{e} 6 \times 4 \mathrm{~m})$. No $2^{\circ}$ e $3^{\circ}$ anos após o plantio das mudas (2005 e 2006, respectivamente), foram estudadas 13 variáveis na cultivarcopa 'Aurora-1', além de sete avaliações trimestrais de diâmetro do tronco, mensuradas a $5 \mathrm{~cm}$ acima e abaixo do ponto de enxertia. Nas condições experimentais adotadas, conclui-se que: a) o diâmetro do tronco de pessegueiros 'Aurora-1' não é influenciado pelo método de propagação do porta-enxerto 'Okinawa' nem pelos diferentes espaçamentos entre plantas; b) não há diferença de diâmetro do tronco entre as medições feitas acima e abaixo do ponto de enxertia e não foram constatados sintomas visíveis de incompatibilidade com a cultivar-copa 'Aurora-1', em ambas as formas de propagação do porta-enxerto; c) os métodos de propagação do porta-enxerto 'Okinawa' estudados não exercem nenhum efeito diferenciado na fenologia, no comprimento de ramos mistos, na produção de gemas floríferas e vegetativas e em sua relação, avaliadas na cv. Aurora-1; d) os diferentes espaçamentos estudados não influenciaram na fenologia, no comprimento de ramos mistos e no número de gemas floríferas por ramo da cv. Aurora-1.

Termos para indexação: Prunus persica, seedling, estaca herbácea, alta densidade.

\section{PROPAGATION METHODS OF THE'OKINAWA' ROOTSTOCKAND SPACING: EFFECTS ON THE TRUNCK DIAMETER, PHENOLOGY AND BUD PRODUCTION IN ‘AURORA-1' PEACH TREES}

\begin{abstract}
The present research had the objective of studying the trunk diameter, the phenology and the bud production in 'Aurora-1' peach trees, budded on 'Okinawa' rootstock propagated by seeds and herbaceous cuttings, in three spacings $(6 \times 2 \mathrm{~m}, 6 \mathrm{x}$ $3 \mathrm{~m}$ and $6 \times 4 \mathrm{~m}$ ). In $2^{\text {nd }}$ and $3^{\text {rd }}$ year after the planting seedlings (2005 and 2006, respectively), 13 variables were studied related to phenology and bud production in 'Aurora-1' peach tree, beyond seven quarterly diameter trunk evaluations, measured $5 \mathrm{~cm}$ above and below of bud point. In the adopted experimental conditions, it was concluded that: a) the trunck diameter of 'Aurora-1' peach trees is neither influenced by propagation method of 'Okinawa' rootstock nor by different in-row spacing; $b$ ) there are no differences on trunk diameter between measurements done above and below of bud point and no visible incompatibility symptoms with 'Aurora1' scion was noticed, in both rootstock propagations methods; c) the studied propagations methods of 'Okinawa' rootstock do not affect the phenology, length of mixed branches, vegetative buds and flower buds production and its relation evaluated in 'Aurora-1' scion; d) the different studied spaces did not influence the phenology, the length of mixed branches and the number of flower buds production per branch of 'Aurora-1' scion.
\end{abstract}

Index terms: Prunus persica, seedling, herbaceous cutting, high density.

Um dos principais problemas que a cultura do pessegueiro apresenta no Brasil é a falta de homogeneidade das plantas, decorrente da propagação sexuada dos porta-enxertos. Essa situação é agravada na região Sul do País, onde são utilizados caroços provenientes de diversas cultivares-copa de maturação tardia, obtidas junto às indústrias que processam pêssego, aumentando ainda mais a variabilidade genética e o vigor dos porta-enxertos (Pereira \& Mayer, 2005). Beckman \& Lang (2003) destacaram que a taxa média de polinização cruzada em pessegueiro é de 2 a $6 \%$ e que o uso de porta-enxertos obtidos por sementes constitui uma importante limitação à uniformidade dos pomares.

Apesar de terem sido realizadas diversas pesquisas sobre enraizamento adventício em porta-enxertos e cultivares-copa de pessegueiro, a formação de pomares comerciais com este método de propagação ainda não se verifica no País, especialmente por exigir maiores conhecimentos técnicos, pelo seu maior custo de produção e pela falta de informações sobre o comportamento no campo de plantas assim propagadas (Pereira \& Mayer, 2005).

Outro problema que se observa na cultura do pessegueiro no Brasil é a baixa produtividade dos pomares. Segundo dados da FAO (2007), o Brasil ocupa o $11^{\circ}$ lugar no mundo em área

'(Trabalho 185-07). Recebido em: 31-07-2007. Aceito para publicação em: 03-03-2008. Apoio financeiro: FAPESP (Processos nos 04/12110-6 e 05/ 50157-7).

${ }^{2}$ Eng. Agr., Dr., Pesquisador da Embrapa Clima Temperado, Rodovia BR 392, Km 78, Caixa Postal 403, CEP 96001-970, Pelotas-RS. alex@cpact.embrapa.br. ${ }^{3}$ Eng. Agr., Dr., Prof. Titular Voluntário do Depto. de Produção Vegetal, FCAV/UNESP, Via de Acesso Prof. Paulo Donato Castellane s/n, CEP 14884900, Jaboticabal-SP. inagrojab@yahoo.com.br.

Rev. Bras. Frutic., Jaboticabal - SP, v. 30, n. 2, p. 560-565, Junho 2008 
colhida com pessegueiro e nectarineira. Entretanto, a produtividade média brasileira, no ano de 2005 , foi de apenas 10,0 t.ha ${ }^{-1}$ o que coloca o País na $21^{\text {a }}$ colocação dentre os de maior produtividade e abaixo da média mundial, que foi de 10,99 t.ha ${ }^{-1} \mathrm{em} 2004$. Apesar dos significativos avanços obtidos com o melhoramento genético (Barbosa et al., 1997; Raseira \& Nakasu, 1998), a persicultura brasileira ainda necessita de novas tecnologias que contribuam para o aumento da produtividade. Neste sentido, observa-se que o adensamento dos pomares pode contribuir de forma significativa, tecnologia já bastante estudada e consolidada no Brasil na cultura da macieira, viabilizada principalmente com o uso de porta-enxertos clonais anões (Denardi, 2002). O uso de seedlings na formação de porta-enxerto não é mais recomendado para a macieira, por apresentar efeito imprevisível no vigor, na reação às doenças e pragas de solo, por induzir tardiamente o início da frutificação, a plena produção e a baixa produtividade, além do insatisfatório tamanho dos frutos e uniformidade das plantas (Denardi \& Leite, 1992).

$\mathrm{Na}$ cultura do pessegueiro, também se constata a tendência de aumento na densidade de plantio (Caser et al., 2000). Alguns estudos foram realizados no Instituto Agronômico de Campinas com a poda drástica anual após a colheita em pomares com densidades de até 3.333 plantas por hectare, que demonstraram viabilidade somente em cultivares precoces, com ciclo menor do que 100 dias (Barbosa et al., 1990a; Barbosa et al., 1990b). Com o uso de poda drástica a cada dois anos, em espaçamento de 4 x 1,5 m (1.667 pl.ha-1), Barbosa et al. (1999) verificaram que a cultivar Aurora-1 produziu, em média, 9,2 kg.planta ${ }^{-1}$. Entretanto, apesar dos bons resultados obtidos com estas pesquisas, essas tecnologias ainda não estão sendo utilizadas em grande escala pelos persicultores da região Sudeste do Brasil.

Diante da carência de conhecimentos técnicos sobre o uso de porta-enxerto clonal na cultura do pessegueiro sob alta densidade de plantio, idealizou-se o presente trabalho que teve por objetivo estudar o diâmetro do tronco, a fenologia e a produção de gemas em pessegueiros 'Aurora-1', enxertados no porta-enxerto 'Okinawa' propagado por sementes e por estacas herbáceas, em três espaçamentos entre plantas.

Foram utilizadas mudas de pessegueiro [Prunus persica (L.) Batsch] cv. Aurora-1 (Ojima et al., 1989), enxertadas pelo método de borbulhia em escudo modificada (Pereira \& Mayer, 2005). O porta-enxerto utilizado foi a cv. Okinawa [Prunus persica (L.) Batsch], propagada por dois métodos: enraizamento de estacas herbáceas em câmara de nebulização intermitente, com o uso de $2.000 \mathrm{mg} . \mathrm{L}^{-1}$ de ácido indolbutírico (Nachtigal, 1999) e por germinação de sementes estratificadas em geladeira (Pereira \& Mayer, 2005). Todos os porta-enxertos foram mantidos em sacos plásticos perfurados $(28 \times 18 \mathrm{~cm})$ contendo substrato comercial (Rendmax Citrus $^{\circledR}$ ), em viveiro com piso cimentado e coberto com sombrite $50 \%$.

O experimento foi instalado em condições de campo, na Fazenda Santa Alzira, Município de Vista Alegre do Alto-SP, em Argissolo Vermelho-Amarelo eutrófico de textura arenosa média (Oliveira et al., 1999). O preparo do solo consistiu de aração, gradagem, adubação de base e calagem, conforme recomendações técnicas (Raij et al., 1996; Pereira et al., 2002). O calcário foi aplicado em todo o terreno e incorporado. Após o preparo, foram feitas as covas $(50 \times 50 \times 50 \mathrm{~cm})$, de acordo com o espaçamento de cada parcela $(6 \times 2 \mathrm{~m}, 6 \times 3 \mathrm{~m}$ ou $6 \times 4 \mathrm{~m})$. Em cada cova foram aplicados: $20 \mathrm{~kg}$ de esterco de bovinos curtido, 1 a $1,5 \mathrm{~kg}$ de superfosfato simples e $60 \mathrm{~g}$ de $\mathrm{K}_{2} \mathrm{O}$ (Pereira et al., 2002), que permaneceram em repouso por 30 dias. Transcorrido este período, as mudas foram transplantadas em agosto de 2003, mantendo-se o torrão intacto. Em seguida, as hastes principais foram podadas a $50 \mathrm{~cm}$ de altura, objetivando a brotação dos ramos laterais.

Foram realizados todos os tratos culturais recomendados para a cultura do pessegueiro na Microrregião de Jaboticabal-SP, inclusive com a poda de renovação após a colheita e irrigação por microaspersão (Pereira et al., 2002). No período de avaliações, as podas de frutificação foram realizadas entre os dias 11 e 13 de julho de 2005 e 30 de junho e $1^{\circ}$ de julho de 2006, aplicando-se, em seguida, a cianamida hidrogenada na dose de 0,29\% de i.a. (Dormex ${ }^{\circledR}$ a 0,6 \%) (Nienow, 1997; Pereira et al., 2002).

As avaliações de diâmetro do tronco foram realizadas a cada três meses, entre os 24 meses (agosto de 2005) e 41 meses (fevereiro de 2007) após o plantio das mudas. Foi eleita uma planta da área útil, representativa de cada parcela, e mensurado o diâmetro com paquímetro a $5 \mathrm{~cm}$ acima e abaixo do ponto de enxertia, expressando-se os resultados em $\mathrm{mm}$. Para a análise estatística desta variável, adotou-se o esquema fatorial $2 \times 3 \times 2$, com os seguintes fatores e níveis: método de propagação do porta-enxerto 'Okinawa' (semente e estaca herbácea), espaçamento entre plantas $(6 \times 2 \mathrm{~m}, 6 \times 3 \mathrm{~m}$ e $6 \times 4 \mathrm{~m})$ e posição da leitura do diâmetro (acima e abaixo do ponto de enxertia).

A fenologia da cv. Aurora-1 foi estudada em 2005 e em 2006. Partindo-se das datas de aplicação da cianamida hidrogenada, foram assinaladas as datas e o número de dias transcorridos para o início da floração (5 a $10 \%$ das flores abertas). Assinalaram-se também as datas de plena floração (50 a $70 \%$ das flores abertas), final da floração ( 90 a $100 \%$ das flores abertas) e a duração total do período de floração, expresso em dias. O período de colheita foi determinado com as datas da primeira colheita comercial dos frutos (início da colheita) e última colheita comercial (final da colheita) e o número de dias transcorridos entre ambas. $\mathrm{O}$ ciclo foi determinado pela contagem do número de dias transcorridos entre a data da plena floração e a data da metade do período de colheita (Nienow, 1997).

O comprimento dos ramos e a produção de gemas foram avaliados antes das podas de produção (30-06 a 04-07-2005 e 2106 a 26-06-2006), ambas com aproximadamente sete meses após a poda de renovação. Foram identificados 20 ramos mistos em uma planta representativa de cada parcela, na área útil, sendo cinco ramos em cada quadrante, localizados no terço mediano da planta. Nestes ramos, foi mensurado o comprimento com fita métrica, expressando-se em $\mathrm{cm}$. O número de gemas floríferas e de gemas vegetativas de cada ramo misto marcado foi determinado por contagem, de acordo com sua típica morfologia, o que permitiu a distinção (Sachs \& Campos, 1998). A partir dessas contagens e do comprimento de cada ramo, os dados foram 
padronizados e expressos em número de gemas floríferas ou vegetativas por $30 \mathrm{~cm}$ de ramo. A partir do número total de gemas floríferas e vegetativas contidas em cada ramo, foi calculada a relação entre elas por divisão.

$O$ experimento foi instalado de acordo com o delineamento experimental de blocos ao acaso, esquema fatorial $2 \times 3$, sendo o fator método de propagação do porta-enxerto 'Okinawa' composto por dois níveis (semente e estaca herbácea) e o fator espaçamento de plantio por três níveis $(6 \times 2 \mathrm{~m}, 6 \times 3 \mathrm{~m}$ e $6 \times 4 \mathrm{~m}$ ). Foram adotadas quatro repetições, totalizando 24 parcelas. Cada parcela foi constituída por 6; 4 e 3 plantas, respectivamente, para cada espaçamento acima citado, de modo que cada parcela ocupou uma área de $72 \mathrm{~m}^{2}$, resultando em área total do experimento de $1.728 \mathrm{~m}^{2}$. Os dados foram submetidos à análise de variância, pelo teste $\mathrm{F}$, e as médias comparadas pelo teste de Tukey, ao nível de $5 \%$ de probabilidade.

Com os valores obtidos nas sete leituras trimestrais realizadas para o diâmetro do tronco, pode-se observar que os métodos de propagação adotados para o porta-enxerto 'Okinawa' não induziram diferenças significativas em nenhuma das avaliações realizadas (Tabela 1). Esses resultados evidenciam o potencial de uso do 'Okinawa' propagado por estacas herbáceas, por não apresentar nenhum sinal de incompatibilidade na região de enxertia ou na copa e por apresentar satisfatório crescimento do tronco, similar ao tradicional 'Okinawa' propagado por sementes. Beckman et al. (2006) também não observaram diferenças significativas na área transversal do tronco entre 'Guardian' propagado por sementes e por estacas, nas avaliações realizadas até o $6^{\circ}$ ano. No presente estudo, destaca-se também a baixa taxa de crescimento do tronco no período da estação seca, em ambos os porta-enxertos, comparando-se os valores das avaliações realizadas em maio e em agosto de 2006. Verificase que, mesmo com o uso da irrigação por microaspersão e com temperatura média do ar e insolação elevadas neste período (Volpe, 2006), as plantas praticamente paralisam seu crescimento durante o inverno ameno típico da região. Também não houve efeito significativo dos diferentes espaçamentos estudados no diâmetro do tronco, nas sete avaliações realizadas (Tabela 1). Esses resultados revelam que, nos primeiros 41 meses após o transplantio das mudas, os espaçamentos reduzidos $(6 \times 3 \mathrm{~m}$ e 6 x $2 \mathrm{~m}$ ) não diminuíram o diâmetro do tronco, em relação ao espaçamento tradicional de $6 \times 4 \mathrm{~m}$ recomendado na Microrregião de Jaboticabal (Pereira et al., 2002).

Não houve diferença significativa de diâmetro do tronco entre as avaliações realizadas acima e abaixo do ponto de enxertia (Tabela 1). Esse fato evidencia a satisfatória união entre portaenxerto e copa, sem sintomas de engrossamento na região da enxertia, em ambos os métodos de propagação do porta-enxerto estudados. Segundo Hartmann et al. (1997), o diâmetro do tronco e a presença de deformações acima ou abaixo do ponto de enxertia são dois dos critérios utilizados nas avaliações de compatibilidade entre copa e porta-enxerto.

Com relação à fenologia da cv. Aurora-1, pode-se observar que nenhuma das variáveis estudadas foi influenciada pelos métodos de propagação ou pelos espaçamentos testados, tanto em 2005 (Tabela 2) como em 2006 (Tabela 3). Segundo Beckman
\& Lang (2003), o efeito do porta-enxerto na data de floração de uma copa da mesma espécie normalmente é sutil ou não detectável, ao passo que, quando utilizado um porta-enxerto de outra espécie ou um híbrido interespecífico, aumentam-se as chances de se produzir um efeito significativo na data de floração. Durner \& Goffreda (1992) salientam que diferentes porta-enxertos podem influenciar na fenologia de gemas floríferas, como datas de floração, taxas de desenvolvimento e, conseqüentemente, a produção.

Observa-se, que em 2006, o período de floração, o período de colheita e o ciclo foram menores do que os observados em 2005. As reduções de sete dias no período de floração, de 13 dias no período de colheita e de três dias no ciclo, devem-se às condições climáticas adversas, ocorridas em 2006, que contribuíram para a queda precoce das pétalas e também anteciparam o final da colheita. No ano de 2006, observou-se que, com raras exceções, os meses da estação seca (entre abril e setembro) apresentaram menor umidade relativa do ar, menor precipitação pluviométrica, menor número de dias com chuva e maior insolação, comparativamente à média histórica da região do período de 1971-2000 (Volpe, 2006). No ano de 2005, as condições climáticas da região foram mais favoráveis à frutificação do pessegueiro, especialmente com relação à umidade relativa do ar, que apresentou valores acima da média histórica (Volpe, 2006). Para cultivares com baixa exigência em frio e com período entre floração e colheita menor do que 100 dias, o aumento ou diminuição de $1{ }^{\circ} \mathrm{C}$ na temperatura média dos dois primeiros meses após o florescimento reflete em cinco dias de antecipação ou atraso na data da colheita, respectivamente (Sherman \& Beckman, 2003).

Com os dados de fenologia (Tabelas 2 e 3), é possível constatar que, na Microrregião de Jaboticabal-SP, o ciclo da cv. Aurora-1 (entre 82 e 85 dias) é menor em relação a outras regiões produtoras do Estado de São Paulo, sendo esta mais uma vantagem comparativa. Em Jundiaí, o ciclo dessa cultivar varia entre 104 e 115 dias, e, em Limeira, o ciclo é de 95 dias (Ojima et al., 1989). Com isso, comprova-se que a Microrregião de Jaboticabal apresenta condições climáticas que favorecem a redução do ciclo e que permitem a produção bem precoce da cv. Aurora-1 (Nienow, 1997; Pereira et al., 2002). Deve-se destacar, entretanto, que o ciclo da 'Aurora-1' varia de ano para ano, em função das variações térmicas ocorridas entre a floração e a colheita. Em Taiúva-SP, Nienow (1997) constatou que o ciclo variou entre 83 e 92 dias em 1995 e entre 85 e 92 dias em 1996.

O método de propagação do porta-enxerto também não influenciou significativamente nas variáveis comprimento do ramo misto, número de gemas floríferas e vegetativas por ramo e na relação entre elas, tanto em 2005 como em 2006. Assim como nas variáveis anteriores, estes dados comprovam a qualidade de porta-enxertos 'Okinawa' propagados por enraizamento de estacas herbáceas, equiparando-se ao tradicional 'Okinawa' propagado por sementes. Estas constatações assemelham-se às obtidas por Beckman et al. (2006) com a cv. Guardian propagada por sementes e por estacas, pois também não verificaram vantagem ou desvantagem entre ambos os métodos na cultivarcopa Cresthaven, conduzida em alta densidade. 
Os diferentes espaçamentos estudados (Tabela 4) também não exerceram influência significativa nas variáveis comprimento de ramo misto e número de gemas floríferas, tanto em 2005 como em 2006. Esses dados revelam a uniformidade do crescimento dos ramos mistos após a poda de renovação, bem como a uniforme produção de gemas de flor, independentemente do espaçamento entre as plantas. Para a variável número de gemas vegetativas, não se detectou diferença estatística em 2005, entretanto essa variável foi afetada significativamente pelos espaçamentos de forma diretamente proporcional em 2006 (Tabela $4)$. Dessa forma, verifica-se que as plantas que receberam maior insolação $(6 \times 4 \mathrm{~m})$ induziram maior produção de gemas vegetativas em 2006, ano em que as condições climáticas apresentaram temperatura média, umidade relativa do ar e insolação acima da média histórica da região (Volpe, 2006).

Os espaçamentos estudados influenciaram significativamente na relação entre gemas floríferas/vegetativas da cv. Aurora-1 (Tabela 4). Em 2005, o espaçamento de 6 x 4 m apresentou a maior relação $(0,89)$, comparativamente ao espaçamento de 6 × 2 m $(0,77)$. Entretanto, em 2006, o resultado foi o inverso, ou seja, a maior relação foi obtida no espaçamento de $6 \times 2 \mathrm{~m}(1,01)$. Observa-se que essa variável foi afetada pela maior produção de gemas vegetativas no espaçamento de $6 \times 4$ m, obtida em 2006 (26,37), que resultou na menor relação gemas floríferas/vegetativas $(0,80)$.
Constatou-se que o número de gemas vegetativas por 30 $\mathrm{cm}$ de ramo é sempre maior do que o número de gemas floríferas por $30 \mathrm{~cm}$ de ramo, nos dois anos de avaliações realizadas, situação decorrente da quase totalidade de gemas vegetativas existentes no primeiro terço dos ramos em 'Aurora-1'. Uma elevada produção de gemas vegetativas é desejável em regiões quentes, por apresentar maior potencial de brotação para promover o sombreamento dos ramos, dos frutos e das pernadas, além de suprir em fotoassimilados o crescimento dos frutos (Pereira et al., 2002).

Nas condições experimentais adotadas, conclui-se que: a) o diâmetro do tronco de pessegueiros 'Aurora-1' não é influenciado pelo método de propagação do porta-enxerto 'Okinawa' nem pelos diferentes espaçamentos entre plantas; $b$ ) não há diferença de diâmetro do tronco entre as medições feitas acima e abaixo do ponto de enxertia e não foram constatados sintomas visíveis de incompatibilidade com a cultivar-copa 'Aurora-1', em ambas as formas de propagação do porta-enxerto; c) os métodos de propagação do porta-enxerto 'Okinawa' estudados não exercem nenhum efeito diferenciado na fenologia, no comprimento de ramos mistos, na produção de gemas floríferas e vegetativas e em sua relação, avaliadas na cv. Aurora$1 ;$ d) os diferentes espaçamentos estudados não influenciam na fenologia, no comprimento de ramos mistos e no número de gemas floríferas por ramo da cv. Aurora-1.

TABELA 1 - Efeito do método de propagação do porta-enxerto 'Okinawa', do espaçamento entre plantas e da posição de leitura no diâmetro do tronco (mm) de pessegueiros 'Aurora-1' (a partir de 24 meses após o transplantio das mudas), em sete avaliações trimestrais consecutivas. Vista Alegre do Alto-SP, 2007.

\begin{tabular}{|c|c|c|c|c|c|c|c|}
\hline \multirow{2}{*}{$\begin{array}{c}\text { Método } \\
\text { de } \\
\text { propagação }\end{array}$} & \multicolumn{7}{|c|}{ Diâmetro do tronco $(\mathrm{mm})$} \\
\hline & $\begin{array}{l}\text { Ago/2005 } \\
(24 \text { meses })\end{array}$ & $\begin{array}{l}\text { Nov/2005 } \\
(27 \text { meses })\end{array}$ & $\begin{array}{c}\text { Fev/2006 } \\
(30 \text { meses })\end{array}$ & $\begin{array}{l}\text { Maio/2006 } \\
\text { (33 meses) }\end{array}$ & $\begin{array}{l}\text { Ago/2006 } \\
(36 \text { meses })\end{array}$ & $\begin{array}{l}\text { Nov/2006 } \\
\text { (39 meses) }\end{array}$ & $\begin{array}{c}\text { Fev/2007 } \\
\text { (41 meses) }\end{array}$ \\
\hline semente & $96,50 \mathrm{a}$ & $109,97 \mathrm{a}$ & $118,79 \mathrm{a}$ & $127,60 \mathrm{a}$ & $127,90 \mathrm{a}$ & $137,90 \mathrm{a}$ & $153,27 \mathrm{a}$ \\
\hline estaca herb. & $96,74 \mathrm{a}$ & $107,90 \mathrm{a}$ & $121,09 \mathrm{a}$ & $130,67 \mathrm{a}$ & $132,46 \mathrm{a}$ & $140,03 \mathrm{a}$ & $154,14 \mathrm{a}$ \\
\hline $\mathrm{F}_{\text {método }}$ & $0,0064^{\mathrm{ns}}$ & $0,5545^{\mathrm{ns}}$ & $0,5638^{\mathrm{ns}}$ & $0,5923^{\mathrm{ns}}$ & $1,3812^{\mathrm{ns}}$ & $0,2967^{\mathrm{ns}}$ & $0,0369^{\mathrm{ns}}$ \\
\hline \multicolumn{8}{|l|}{ Espaçamento } \\
\hline $6 \times 2 \mathrm{~m}$ & $93,33 \mathrm{a}$ & $106,59 \mathrm{a}$ & $116,66 \mathrm{a}$ & $125,25 \mathrm{a}$ & $127,28 \mathrm{a}$ & $133,50 \mathrm{a}$ & $145,06 \mathrm{a}$ \\
\hline $6 \times 3 \mathrm{~m}$ & $96,61 \mathrm{a}$ & $109,13 \mathrm{a}$ & $122,94 \mathrm{a}$ & $132,62 \mathrm{a}$ & $133,05 \mathrm{a}$ & $143,21 \mathrm{a}$ & $157,49 \mathrm{a}$ \\
\hline $6 \times 4 m$ & $99,93 \mathrm{a}$ & $111,08 \mathrm{a}$ & $120,23 \mathrm{a}$ & $129,54 \mathrm{a}$ & $130,21 \mathrm{a}$ & $140,19 \mathrm{a}$ & $158,57 \mathrm{a}$ \\
\hline $\mathrm{F}_{\text {espaçamento }}$ & $1,6030^{\mathrm{ns}}$ & $0,8770^{\mathrm{ns}}$ & $1,4130^{\mathrm{ns}}$ & $1,1532^{\mathrm{ns}}$ & $0,7377^{\mathrm{ns}}$ & $2,1471^{\mathrm{ns}}$ & $3,6534 *$ \\
\hline \multicolumn{8}{|c|}{ Posição da leitura em relação ao ponto de enxertia } \\
\hline acima & $96,47 \mathrm{a}$ & $109,23 \mathrm{a}$ & $118,26 \mathrm{a}$ & $128,91 \mathrm{a}$ & $129,78 \mathrm{a}$ & $137,23 \mathrm{a}$ & $153,78 \mathrm{a}$ \\
\hline abaixo & $96,77 \mathrm{a}$ & $108,64 \mathrm{a}$ & $121,63 \mathrm{a}$ & $129,36 \mathrm{a}$ & $130,57 \mathrm{a}$ & $140,70 \mathrm{a}$ & $153,63 \mathrm{a}$ \\
\hline $\mathrm{F}_{\text {posicão }}$ & $0,0096^{\mathrm{ns}}$ & $0,0460^{\mathrm{ns}}$ & $1,2080^{\mathrm{ns}}$ & $0,0130^{\mathrm{ns}}$ & $0,0411^{\mathrm{ns}}$ & $0,7835^{\mathrm{ns}}$ & $0,0010^{\mathrm{ns}}$ \\
\hline $\mathrm{F}_{\text {mét.x esp. }}$ & $0,5648^{\mathrm{ns}}$ & $0,8610^{\mathrm{ns}}$ & $0,9419^{\mathrm{ns}}$ & $0,4965^{\mathrm{ns}}$ & $0,5306^{\mathrm{ns}}$ & $1,9315^{\mathrm{ns}}$ & $0,3978^{\mathrm{ns}}$ \\
\hline $\mathrm{F}_{\text {mét.x posicão }}$ & $2,9700^{\mathrm{ns}}$ & $5,4744 * *$ & $0,9699^{\mathrm{ns}}$ & $0,3525^{\mathrm{ns}}$ & $0,5249^{\mathrm{ns}}$ & $0,3807^{\mathrm{ns}}$ & $0,7702^{\mathrm{ns}}$ \\
\hline $\mathrm{F}_{\text {esp. x posicão }}$ & $0,6106^{\mathrm{ns}}$ & $0,2534^{\mathrm{ns}}$ & $1,4566^{\mathrm{ns}}$ & $0,6957^{\mathrm{ns}}$ & $0,5303^{\mathrm{ns}}$ & $1,3951^{\mathrm{ns}}$ & $0,6996^{\mathrm{ns}}$ \\
\hline $\mathrm{F}_{\text {métxesp.xpos. }}$ & $0,2605^{\mathrm{ns}}$ & $0,6155^{\mathrm{ns}}$ & $0,0897^{\mathrm{ns}}$ & $0,0678^{\mathrm{ns}}$ & $0,1012^{\mathrm{ns}}$ & $0,6798^{\mathrm{ns}}$ & $0,3229^{\mathrm{ns}}$ \\
\hline $\mathrm{F}_{\text {blocos }}$ & $3,8045 *$ & $5,3297 * *$ & $3,7903 *$ & $2,6572^{\mathrm{ns}}$ & $2,7451^{\mathrm{ns}}$ & $1,8474^{\mathrm{ns}}$ & $2,3156^{\mathrm{ns}}$ \\
\hline CV $(\%)$ & 10,80 & 8,82 & 8,85 & 10,67 & 10,33 & 9,76 & 10,22 \\
\hline
\end{tabular}

Médias seguidas por letras distintas, na mesma coluna, diferem entre si,pelo teste de Tukey. * significativo ao nível de $5 \%$ de probabilidade; ** significativo ao nível de $1 \%$ de probabilidade; ns não-significativo. 
TABELA 2 - Data de aplicação da cianamida hidrogenada, número de dias para iniciar a floração, período de floração (início, plena, final e número de dias), período de colheita (início, final e número de dias) e duração do ciclo de pessegueiros 'Aurora1 ' ( $2^{\circ}$ ano após o transplantio das mudas) enxertados em 'Okinawa' propagados por sementes e por estacas herbáceas, sob três espaçamentos entre plantas. Vista Alegre do Alto-SP, 2005.

\begin{tabular}{|c|c|c|c|c|c|c|c|c|c|c|}
\hline \multirow[b]{2}{*}{ Tratamentos } & \multirow{2}{*}{$\begin{array}{c}\text { aplicação } \\
\text { cian. hidrog. }\end{array}$} & \multirow{2}{*}{$\begin{array}{c}\mathrm{n}^{\circ} \text { dias até iniciar } \\
\text { floração }\end{array}$} & \multicolumn{4}{|c|}{ período de floração } & \multicolumn{3}{|c|}{ período de colheita } & \multirow[b]{2}{*}{ ciclo $^{1}$} \\
\hline & & & início & plena & final & $\overline{\text { dias }}$ & início & final & dias & \\
\hline Semente $6 \times 2 \mathrm{~m}$ & $13 / 07 / 2005$ & 14 & $27 / 07$ & $13 / 08$ & $24 / 08$ & 28 & $22 / 10$ & $21 / 11$ & 30 & 85 \\
\hline Semente $6 \times 3 \mathrm{~m}$ & $13 / 07 / 2005$ & 14 & $27 / 07$ & $13 / 08$ & $24 / 08$ & 28 & $22 / 10$ & $21 / 11$ & 30 & 85 \\
\hline Semente $6 \times 4 \mathrm{~m}$ & $13 / 07 / 2005$ & 14 & $27 / 07$ & $13 / 08$ & $24 / 08$ & 28 & $22 / 10$ & $21 / 11$ & 30 & 85 \\
\hline Estaca $6 \times 2 \mathrm{~m}$ & $13 / 07 / 2005$ & 14 & $27 / 07$ & $13 / 08$ & $24 / 08$ & 28 & $22 / 10$ & $21 / 11$ & 30 & 85 \\
\hline Estaca $6 \times 3 m$ & $13 / 07 / 2005$ & 14 & $27 / 07$ & $13 / 08$ & $24 / 08$ & 28 & $22 / 10$ & $21 / 11$ & 30 & 85 \\
\hline Estaca $6 \times 4 \mathrm{~m}$ & $13 / 07 / 2005$ & 14 & $27 / 07$ & $13 / 08$ & $24 / 08$ & 28 & $22 / 10$ & $21 / 11$ & 30 & 85 \\
\hline
\end{tabular}

${ }^{1}$ ciclo $=\mathrm{n}^{\circ}$ de dias transcorridos da plena floração até a data da metade do período de colheita.

TABELA 3 - Data de aplicação da cianamida hidrogenada, número de dias para iniciar a floração, período de floração (início, plena, final e número de dias), período de colheita (início, final e número de dias) e duração do ciclo de pessegueiros 'Aurora$1^{\prime}$ ( $3^{\circ}$ ano após o transplantio das mudas) enxertados em 'Okinawa' propagados por sementes e por estacas herbáceas, sob três espaçamentos entre plantas. Vista Alegre do Alto-SP, 2006.

\begin{tabular}{|c|c|c|c|c|c|c|c|c|c|c|}
\hline \multirow[b]{2}{*}{ Tratamentos } & \multirow{2}{*}{$\begin{array}{c}\text { aplicação } \\
\text { cian. hidrog. }\end{array}$} & \multirow{2}{*}{$\begin{array}{l}\mathrm{n}^{\circ} \text { dias até iniciar } \\
\text { floração }\end{array}$} & \multicolumn{4}{|c|}{ período de floração } & \multicolumn{3}{|c|}{ período de colheita } & \multirow[b]{2}{*}{ ciclo } \\
\hline & & & início & plena & final & $\overline{\text { dias }}$ & início & final & dias & \\
\hline Semente $6 \times 2 \mathrm{~m}$ & $03 / 07 / 2006$ & 18 & $21 / 07$ & $01 / 08$ & $11 / 08$ & 21 & $13 / 10$ & $30 / 10$ & 17 & 82 \\
\hline Semente $6 \times 3 \mathrm{~m}$ & $03 / 07 / 2006$ & 18 & $21 / 07$ & $01 / 08$ & $11 / 08$ & 21 & $13 / 10$ & $30 / 10$ & 17 & 82 \\
\hline Estaca $6 \times 2 \mathrm{~m}$ & $03 / 07 / 2006$ & 18 & $21 / 07$ & $01 / 08$ & $11 / 08$ & 21 & $13 / 10$ & $30 / 10$ & 17 & 82 \\
\hline Estaca $6 \times 3 \mathrm{~m}$ & $03 / 07 / 2006$ & 18 & $21 / 07$ & $01 / 08$ & $11 / 08$ & 21 & $13 / 10$ & $30 / 10$ & 17 & 82 \\
\hline
\end{tabular}

${ }^{1}$ ciclo $=\mathrm{n}^{\circ}$ de dias transcorridos da plena floração até a data da metade do período de colheita.

TABELA 4 - Efeito do método de propagação do porta-enxerto 'Okinawa' e do espaçamento entre plantas de pessegueiro 'Aurora-1' $\left(2^{\circ}\right.$ e $3^{\circ}$ anos após o transplantio das mudas) nas variáveis comprimento de ramos mistos (cm) antes da poda de frutificação, número de gemas floríferas por $30 \mathrm{~cm}$ de ramo, número de gemas vegetativas por $30 \mathrm{~cm}$ de ramo e relação entre gemas floríferas/vegetativas. Vista Alegre do Alto-SP, 2006.

\begin{tabular}{|c|c|c|c|c|c|c|c|c|}
\hline \multirow{2}{*}{$\begin{array}{c}\text { Método } \\
\text { de } \\
\text { propagação }\end{array}$} & \multicolumn{2}{|c|}{$\begin{array}{l}\text { compr. ramo } \\
\text { misto }(\mathrm{cm})\end{array}$} & \multicolumn{2}{|c|}{$\begin{array}{l}\mathrm{n}^{\circ} \text { gemas } \\
\text { floríf. } / 30 \mathrm{~cm}\end{array}$} & \multicolumn{2}{|c|}{$\begin{array}{c}\mathrm{n}^{\circ} \text { gemas } \\
\text { veget. } / 30 \mathrm{~cm}\end{array}$} & \multicolumn{2}{|c|}{$\begin{array}{l}\text { relação gemas } \\
\text { flor./veget. }\end{array}$} \\
\hline & 2005 & 2006 & 2005 & 2006 & 2005 & 2006 & 2005 & 2006 \\
\hline semente & $33,17 \mathrm{a}$ & $36,00 \mathrm{a}$ & $15,37 \mathrm{a}$ & $18,48 \mathrm{a}$ & $19,59 \mathrm{a}$ & $22,11 \mathrm{a}$ & $0,82 \mathrm{a}$ & $0,92 \mathrm{a}$ \\
\hline estaca herbácea & $32,13 \mathrm{a}$ & $34,63 \mathrm{a}$ & $15,68 \mathrm{a}$ & $18,75 \mathrm{a}$ & $20,58 \mathrm{a}$ & $23,07 \mathrm{a}$ & $0,81 \mathrm{a}$ & $0,88 \mathrm{a}$ \\
\hline $\mathrm{F}_{\text {método }}$ & $0,749^{\mathrm{ns}}$ & $1,173^{\mathrm{ns}}$ & $0,419^{\mathrm{ns}}$ & $0,240^{\mathrm{ns}}$ & $3,346^{\mathrm{ns}}$ & $1,287^{\mathrm{ns}}$ & $0,244^{\mathrm{ns}}$ & $0,602^{\mathrm{ns}}$ \\
\hline \multicolumn{9}{|l|}{ Espaçamento } \\
\hline $6 \times 2 \mathrm{~m}$ & $33,44 \mathrm{a}$ & $36,36 \mathrm{a}$ & $14,89 \mathrm{a}$ & $18,31 \mathrm{a}$ & $20,55 \mathrm{a}$ & $19,25 \mathrm{c}$ & $0,77 \mathrm{~b}$ & $1,01 \mathrm{a}$ \\
\hline $6 \times 3 m$ & $32,18 \mathrm{a}$ & $36,66 \mathrm{a}$ & $15,52 \mathrm{a}$ & $18,30 \mathrm{a}$ & $20,62 \mathrm{a}$ & $22,15 \mathrm{~b}$ & $0,79 \mathrm{ab}$ & $0,89 \mathrm{ab}$ \\
\hline $6 \times 4 \mathrm{~m}$ & $32,32 \mathrm{a}$ & $32,93 \mathrm{a}$ & $16,16 \mathrm{a}$ & $19,23 \mathrm{a}$ & $19,10 \mathrm{a}$ & $26,37 \mathrm{a}$ & $0,89 \mathrm{a}$ & $0,80 \mathrm{~b}$ \\
\hline $\mathrm{F}_{\text {espaçamento }}$ & $0,437^{\mathrm{ns}}$ & $3,541^{\mathrm{ns}}$ & $2,335^{\mathrm{ns}}$ & $1,177^{\mathrm{ns}}$ & $3,392^{\mathrm{ns}}$ & $23,846 * *$ & $4,589 *$ & $7,178^{* *}$ \\
\hline $\mathrm{F}_{\text {método } \mathrm{x} \text { esp. }}$ & $0,463^{\mathrm{ns}}$ & $0,850^{\mathrm{ns}}$ & $0,426^{\mathrm{ns}}$ & $0,004^{\mathrm{ns}}$ & $0,044^{\mathrm{ns}}$ & $0,614^{\mathrm{ns}}$ & $0,361^{\mathrm{ns}}$ & $0,249^{\mathrm{ns}}$ \\
\hline $\mathrm{F}_{\text {blocos }}$ & $2,726^{\mathrm{ns}}$ & $2,935^{\mathrm{ns}}$ & $2,019^{\mathrm{ns}}$ & $5,953 * *$ & $3,936 *$ & $3,018^{\mathrm{ns}}$ & $1,966^{\mathrm{ns}}$ & $8,749 * *$ \\
\hline CV (\%) & 9,03 & 8,83 & 7,58 & 7,46 & 6,58 & 9,18 & 10,63 & 12,27 \\
\hline
\end{tabular}

Médias seguidas por letras distintas, na mesma coluna, diferem entre si, pelo teste de Tukey. * não-significativo ao nível de $5 \%$;** significativo ao nível de $1 \%$; ns não significativo. 


\section{AGRADECIMENTOS}

Os autores agradecem à FAPESP (Processos $n^{\text {os }} 04 /$ 12110-6 e 05/50157-7) e ao Sr. Valdenir Rossi, proprietário da Fazenda Santa Alzira (Vista Alegre do Alto-SP), pelo apoio.

\section{REFERÊNCIAS}

BARBOSA, W.; CAMPO DALL'ORTO, F.A.; OJIMA, M. O pessegueiro no sistema de pomar compacto: V. Pesquisas do Instituto Agronômico na década de 80. O Agronômico, Campinas, v.42, n.1, p.35-44, 1990a.

BARBOSA, W.; CAMPO DALL'ORTO, F.A.; OJIMA, M.; SAMPAIO, V.R. O pessegueiro no sistema de pomar compacto: III. Épocas de poda drástica na diferenciação floral. Bragantia, Campinas, v.49, n.1, p.147-155, 1990 b.

BARBOSA, W.; OJIMA, M.; CAMPO DALL'ORTO, F.A.; RIGITANO, O.; MARTINS, F.P.; SANTOS, F.P.; CASTRO, J.L. Melhoramento do pessegueiro para regiões de clima subtropical-temperado: realizações do Instituto Agronômico no período de 1950 a 1990. Campinas, Instituto Agronômico, 1997. 22p. (Documentos IAC, 52).

BARBOSA, W.; CAMPO DALL'ORTO, F.A.; OJIMA, M.; SANTOS, R.R. dos.; KALIL, G.P da C. FAHL, J.I.; CARELLI, M.L.C. O pessegueiro em pomar compacto. IX. Dez anos de produção de cultivares sob poda drástica bienal. Pesquisa Agropecuária Brasileira, Brasília, v.34, n.1, p.69-76, 1999.

BECKMAN, T.G.; LANG, G.A. Rootstock breeding for stone fruits. Acta Horticulturae, Wageningen, n.622, p.531-551, 2003.

BECKMAN, T.G.; NYCZEPIR, A.P.; MYERS, S.C. Performance of peach rootstocks propagated as seedlings vs. cuttings. Acta Horticulturae, Wageningen, n.713, p.289-293, 2006.

CASER, D.V.; CAMARGO, A.M.M.P. de.; AMARO, A.A. Densidades de plantio em culturas perenes na agricultura paulista. Informações Econômicas, São Paulo, v.30, n.7, p.45-53, 2000.

DENARDI, F.; LEITE, G.B. Seedling como porta-enxerto em macieira. HortiSul, Pelotas, v.2, n.4, p.33-35, 1992.

DENARDI, F. Porta-enxertos. In: EPAGRI. A cultura da macieira. Florianópolis: EPAGRI, 2002.p.169-227.

DURNER, E.F.; GOFFREDA, J.C. Rootstock-induced differences in flower bud phenology in peach. Journal American Society for Horticultural Science, Alexandria, v.117, n.5, p.690-697, 1992.

FAO. Melocotones y nectarinas: producción, área y rendimiento. 2007. Disponível em: <http://www.faostat.fao.org/site/408/ DesktopDefault.aspx?PageID=408>. Acesso em: 26 mar. 2007.
HARTMANN, H.T.; KESTER, D.E.; DAVIES JR., F.T.; GENEVE, R.L. Plant propagation: principles and practices. $6^{\text {th }}$ ed. New Jersey: Prentice Hall, 1997. 770p.

NACHTIGAL, J.C. Obtenção de porta-enxertos 'Okinawa' e de mudas de pessegueiro (Prunus persica (L.) Batsch) utilizando métodos de propagação vegetativa. 1999. 165f. Tese (Doutorado em Agronomia) - Faculdade de Ciências Agrárias e Veterinárias, Universidade Estadual Paulista, Jaboticabal, 1999.

NIENOW, A.A. Comportamento morfológico, fenológico e produtivo de cultivares de pessegueiro (Prunus persica (L.) Batsch), submetidos à poda de renovação após a colheita, na região de Jaboticabal, SP. 1997. 171f. Tese (Doutorado em Agronomia) - Faculdade de Ciências Agrárias e Veterinárias, Universidade Estadual Paulista, Jaboticabal, 1997.

OJIMA, M.; CAMPO DALL'ORTO, F.A.; BARBOSA, W.; MARTINS, F.P.; SANTOS, R.R.; RIGITANO, O. 'Aurora-1' e 'Aurora-2': novas cultivares de pêssego doce de polpa amarela. In: CONGRESSO BRASILEIRO DE FRUTICULTURA, 10., 1989, Fortaleza. Anais... Fortaleza: SBF, 1989. p.422-425.

OLIVEIRA, J.B. de; CAMARGO, M.N.; ROSSI, M.; CALDERANO-FILHO, B. Mapa pedológico do Estado de São Paulo: legenda expandida. Campinas: Instituto Agronômico; Rio de Janeiro: Embrapa-Solos, 1999. 64p.

PEREIRA, F.M.; NACHTIGAL, J.C.; ROBERTO, S.R. Tecnologia para a cultura do pessegueiro em regiões tropicais $\mathrm{e}$ subtropicais. Jaboticabal: Funep, 2002. 62p.

PEREIRA, F.M.; MAYER, N.A. Pessegueiro: tecnologias para a produção de mudas. Jaboticabal: Funep, 2005. 65p.

RAIJ, B.V.; CANTARELLA, H.; QUAGGIO, J.A.; FURLANI, A.M.C. Recomendações de adubação e calagem para o Estado de São Paulo. Campinas: IAC, 1996. (Boletim Técnico, 100).

RASEIRA, M. do C.B.; NAKASU, B. Cultivares: descrição e recomendação. In: MEDEIROS, C.A.B.; RASEIRA, M. do C.B. A cultura do pessegueiro. Brasília: Embrapa SPI; Pelotas: Embrapa CPACT, 1998. p.29-99.

SACHS, S.; CAMPOS, A.D. O pessegueiro. In: MEDEIROS, C.A.B.; RASEIRA, M. do C.B. A cultura do pessegueiro. Brasília: Embrapa SPI; Pelotas: Embrapa CPACT, 1998. p.14-19.

SHERMAN, W.B.; BECKMAN, T.G. Climatic adaptation in fruit crops. Acta Horticulturae, Wageningen , n.622, p.411-428, 2003.

VOLPE. C.A. (Coord.). Estação agroclimatológica. 2006. Disponível em: <http//www.exatas.fcav.unesp.br/estacao>. Acesso em: 13 fev. 2007. 